\title{
Moisés Bertoni e o Povoamento da América: primeiras questões ${ }^{1}$
}

\author{
Moisés Bertoni y lo Poblamiento de la América: primeras cuestiones \\ Moisés Bertoni and the America Settlement: first questions
}

\author{
Ms. Wagner Henrique Neres Fiuza²
}

\begin{abstract}
Resumo
Qual a origem dos povos que habitavam a América quando da chegada dos europeus? Entre as mais diferentes respostas já construídas nos últimos séculos, a obra La Civilización Guarani (1922) foi escrita a partir de relatos da América colonial e de análises da antropologia linguística do cientista suíço-paraguaio Moisés Bertoni. Nela, Bertoni objetivou localizar a origem dos povos guaranis como sinônimo da origem humana na América. Neste percurso, motivado pela crença na ideia de uma ciência universal, sua pesquisa procurou estabelecer hipóteses sobre o povoamento da América do Sul. Imerso em um vasto campo de experimentação científica e intenso confronto entre empiria e teoria, os debates de que participou sobre a origem dos povos americanos pode ter como efeito colateral a discussão sobre a origem, a identidade e o lugar social das populações indígenas no estado-nação moderno. Até este momento da pesquisa, pode-se afirmar que a ciência produzida por Bertoni insere-se numa rede de (re)significação do passado colonial e indígena.
\end{abstract}

Palavras-Chave: América Latina; Antropologia; Ciência; Civilização Guarani; Moisés Bertoni.

\section{Resumen}

¿Cuál es el origen de los pueblos que habitaban América a la llegada de los europeos? Entre las más diversas respuestas ya construidas en los últimos siglos, la obra La Civilización Guaraní (1922) fue escrita a partir de relatos de la América colonial y de análisis de la antropología lingüística del científico suizo-paraguayo Moisés Bertoni. En ella, Bertoni objetivó localizar el origen de los pueblos guaraníes como sinónimo del origen humano en América. En este recorrido, motivado por la creencia en la idea de una ciencia universal, su investigación buscó establecer hipótesis sobre el poblamiento de América del Sur. Inmersado en un vasto campo de experimentación científica e intenso enfrentamiento entre empiria y teoría, los debates de que participó sobre el origen de los pueblos americanos puede tener como efecto colateral la discusión sobre el origen, la identidad y el lugar social de las poblaciones indígenas en el estado-nación moderno. Hasta este momento de la investigación, se puede afirmar que la ciencia producida por Bertoni se inserta en una red de (re) significación del pasado colonial e indígena.

Palabras claves: América Latina; Antropología; Ciencia; La Civilización Guaraní; Moisés Bertoni.

\begin{abstract}
What is the origin of the peoples who inhabited America when the Europeans arrived? Among the most different answers ever constructed in the last centuries, the work La Civilización Guarani (1922) was written on the basis of colonial American accounts and analyzes of the linguistic anthropology of the Swiss-Paraguayan scientist Moisés Bertoni. In it, Bertoni aimed to locate the origin of the Guarani peoples as synonymous with human origin in America. Immersed in a vast field of scientific experimentation and intense confrontation between empiria and theory, the debates of which he participated in the origin of the American peoples may have as a side effect the discussion on the origin, identity and social place of the indigenous populations in the modern
\end{abstract}

\footnotetext{
1 Artigo apresentado no Simpósio Temático: Repensar, Refletir, Interpretar e Reinterpretar a Memória, Identidade e o Patrimônio Cultural da América Colonial durante o II Seminário Latino-Americano de Estudos em Cultura - SEMLACult em Foz do Iguaçu/PR, Brasil, 2018.

${ }^{2}$ Mestre em História e Regiões; Doutorando no Programa de Pós-Graduação em História da Universidade Estadual do Oeste do Paraná (UNIOESTE); Guarapuava, Paraná, Brasil; wagnerunicentro@ hotmail.com.
} 
nation-state. Until this moment of the research, one can affirm that the science produced by Bertoni is inserted in a network of (re) signification of the colonial and indigenous past.

Keywords: Latin America; Anthropology; Science; The Guaraní Civilization; Moisés Bertoni.

\section{Introdução}

Qual a origem dos povos americanos? Esta é uma pergunta que ganhou em complexidade e profundidade conforme as caravelas e naus europeias fizeram conhecer um continente gigantesco e incógnito na história e geografia europeias. Tão logo a cartografia europeia sobre a América se desenvolveu, a principal explicação esteve numa passagem de povos originários pelo Estreito de Bering, uma pequena faixa de mar que separa os pontos mais próximos de terra firme entre a Ásia e a América do Norte.

O elemento que solidificava a interpretação geral de que todos os povos americanos tinham a mesma origem era o fenótipo das populações indígenas ser muito parecido com o fenótipo asiático, indicando algum parentesco, ainda que longínquo. Implícita nesta interpretação estava uma visão eurocêntrica de que as populações americanas eram de um mesmo povo, ou melhor, a mesma coisa, confundida entre a paisagem opulenta e selvagem da natureza, marcados pelo atraso tecnológico e pelo paganismo religioso, e, como veremos, passíveis da conquista.

A dúvida atravessou séculos e nestes entremeios ganhou novos contornos a partir da revisita à esta questão com novos olhares. Ao alcançar o século XIX, a pergunta base passa pelo olhar cada vez mais escrutinador da ciência. É nesse momento que alguns pesquisadores passam a colocar em xeque a tese de que o povoamento americano ocorreu pelo estreito de Bering. Assim, o objetivo deste texto é compreender algumas das inquietações e respostas do cientista suíço-paraguaio Moisés Bertoni para o povoamento da América grafadas em sua obra La Civilización Guarani (1922).

\section{A Conquista da América}

A chegada dos europeus no século XVI foi um acontecimento ímpar. Existem diferentes formas de pensar as relações que se seguiram. Em comum, diferentes análises privilegiam pensar o terror da conquista em suas facetas materiais e imateriais, ou seja, como um processo histórico em que a conquista aniquilou culturas inteiras, alterando drasticamente as relações de poder existentes na América pré-colombiana; violando corpos, massacrando comunidades e destruindo materialmente e simbolicamente todo um legado cultural. 
A sanha da conquista envolveu a cruz e a espada e todo um jogo de forças e imaginários constituídos sobre o outro. Para Tzevetan Todorov, por exemplo, a América já havia sido inventada antes de ser encontrada. Isso significa que um dos alicerces do Novo Mundo é uma relação de alteridade entre o eu e o outro, recíproca e simbólica, mas, com significados diferentes para o espanhol Cristóvão Colombo e para asteca Montezuma. Ambos pertenciam a culturas diferentes, que liam o outro a partir de um sistema simbólico e explicativo próprio. Na medida em que esta é ou se torna uma relação desigual, a imagem do outro espanhol fez a passagem do divino para o profano e humano, enquanto que a imagem do outro asteca se tornou de objeto da paisagem em objeto de conquista, uma coisa, um objeto que pode ser tomado e destruído (TODOROV, 1982).

Dos escombros da conquista restaram relatos, diários, correspondências e livros, publicados por europeus ou por não europeus, mas ainda dentro da racionalidade das práticas de escrita europeias. Este entendimento do universo da escrita é postulado por Roger Chartier, que compreende o universo dos livros como intrinsecamente relacionado às práticas de escrita e de leitura, ou seja, leva em consideração o leitor ideal, os mediadores materiais e as instâncias imateriais de censura, a circulação prevista e não prevista das obras (CHARTIER, 2014).

Ora, o período que corresponde à América Colonial é o mesmo em que a Europa leva adiante uma revolução científica. Desde o século XVII a filosofia moderna propunha um rompimento radical com a escolástica medieval, baseada no uso da razão para a contemplação da obra divina. Essa nova maneira de pensar teve no francês René Descartes (1596-1650) um grande representante, para quem o conhecimento deveria ser submetido à experimentação e a racionalização dos dados obtidos de forma empírica e racional. Em busca de uma verdade irrefutável e objetivamente comprovável, a ciência cartesiana serviu de base para o desenvolvimento da ciência nos séculos seguintes, cuja aplicação se concretizou no envio dos naturalistas pelo mundo, para contribuir com os jardins e herbários reais, deslocando o centro da relação saber-poder da religião para a ciência, e legitimando as monarquias reais europeias como centro dos discursos de poder oriundos dos discursos científicos acerca do mundo (FOUCAULT, 2014).

A respeito da origem dos povos americanos, o novo paradigma de produção de conhecimento, com fins de objetividade, neutralidade e o uso de um método científico gerou um problema: como comprovar as hipóteses que se remetem a um tempo que não existe mais? Quais dentre os vestígios que restaram seriam suficientemente confiáveis para uma pesquisa científica sobre o passado colonial? A especialização do conhecimento no século XIX 
contrasta com as "descobertas" de lugares outrora habitados por povos nativos, mas, agora (re)significados como sítios arqueológicos ${ }^{3}$ que faziam sentido no ímpeto científico de conhecer, coligir, colecionar e classificar.

No caso americano, muitas dessas “descobertas" são o retorno aos próprios subprodutos da conquista europeia e do grande genocídio americano. Revirar aqueles escombros fez surgir novas dúvidas quanto ao passado pré-colombiano. O saber advindo dessas expedições e "descobertas" estava inscrito em relações de poder, e, na medida em que este não é apenas disciplinador ou normativo, mas também produtivo (FOUCAULT, 2014), cabe perguntar: que tipo de produções são geradas a partir de discursos científicos acerca dos escombros da conquista da América colonial? Como se passa a buscar reconstruir um passado pré-colombiano? Para pensar tal questão é pertinente um olhar para a obra La Civilización Guarani (1922), assinada por Moisés Bertoni (1857-1929), um ainda jovem cientista suíçoparaguaio de formação acadêmica nas Universidades de Zurique e de Genebra, onde também forjou seu interesse pela América.

\section{Qual a origem dos povo americanos?}

Por volta do ano de 1890, após um período malsucedido na Argentina, chegava ao Paraguai o cientista suíço Moisés Bertoni acompanhado de sua família. Suas motivações científicas incluíam o estabelecimento de uma colônia agrícola e de um laboratório para pesquisar a fauna e a flora da região. Para estabelecer-se, recebeu incentivos como um terreno de 199 hectares de terra às margens do Rio Iguaçu, próximo do Rio Monday, além da promessa de auxílio financeiro para contribuir com o andamento das pesquisas - um compromisso que, quando foi interrompido, teve na produção e venda de alimentos, bem como na venda dos livros produzidos a partir das experiências ali efetivadas, o seu meio de financiamento principal (BUTTURA; NIEMEYER, 2012).

Foi ali, até findar seus dias em 1929, que Moisés Bertoni dedicou sua vida à ciência. Seus temas de interesse foram vastos, e abrangeram a geografia, a meteorologia, a botânica e a antropologia, assinando mais de 500 livros publicados, assim como reunindo atas, anais, cartas e livros que perfizeram uma biblioteca com milhares de itens. Pela vastidão das áreas de interesse e pela quantidade de publicações, que envolveram praticamente todas as suas áreas de interesse, Moisés Bertoni é considerado por seus biógrafos como um dos últimos enciclopedistas (FLECK, 2007).

\footnotetext{
${ }^{3}$ A cidade inca de Macchu Picchu foi encontrada em 1911, por exemplo.
} 
A formação acadêmica de Moisés Bertoni, inclusive coincidiu com a transição de uma ciência iluminista enciclopédica para uma produção de conhecimento científico cada vez mais especializada, em que as grandes áreas de estudo se tornaram, progressivamente, novas disciplinas como a etnologia, a antropologia ou o refinamento da própria arqueologia. Esta reorganização do campo científico e acadêmico europeu contribuiu para realimentar as discussões sobre a origem americana. Se a dúvida era a linha mestra para observar o mundo, o cruzamento dos mais variados dados geológicos, antropométricos, linguísticos, históricos, climatológicos, enfim, dos saberes especializados, permitiria elaborar enredos novos para velhas perguntas e velhas certezas, como a própria questão do povoamento da América précolombiana.

No livro La Civilización Guarani parte I (1922) assinado por Moisés Bertoni é possível compreender um pouco desse debate. Ele representa, em primeiro lugar, o interesse vívido de Bertoni nas populações guaranis que habitavam o Paraguai. Inclusive, apesar de uma grande preocupação climatológica e com a agricultura, é notável o quanto a antropologia e a geografia humana ganham importância na sua produção científica conforme Bertoni envelheceu, inclusive a realização parcial do projeto de três tomos de La Civilización Guarani. O protagonismo da população guarani no Paraguai vivenciado por Bertoni o fez associar as origens americanas às origens guaranis.

Além de sua própria vivência em solo americano, a experiência de viver na América permitiu a Bertoni levar a sério os estudos de campo e os intelectuais que produziam conhecimento empírico nas matas e cidades americanas. $\mathrm{O}$ cruzamento de dados produzidos em diferentes pontos do continente fizeram com que, tanto Moisés Bertoni quanto outros, como o argentino Francisco Ameghino, contestassem a hipótese de povoamento americano via Estreito de Bering, e, por conseguinte, construíssem suas próprias propostas alternativas para pensar a origem do homem americano. Francisco Ameghino, por exemplo, a partir dos dados antropométricos de ossadas encontradas num sítio arqueológico argentino, assim como utilizando-se de conjecturas culturais e históricas, propunha que não só o continente foi povoado do Sul para o Norte, mas, que a própria espécie humana se originou no continente americano e depois se espalhou pelo mundo (BERTONI, 1922).

Já Moisés Bertoni, a partir dos métodos da antropologia linguística e da antropometria, situava a origem do homem americano no continente asiático. Entretanto, mediante os achados arqueológicos no Chile e no Brasil, inclusive os fósseis encontrados por Peter Lund (1801-1880) em Lagoa Lapa do Santo, assomados à literatura que tinha acesso, Bertoni se viu em uma encruzilhada epistemológica: dadas as suas premissas, não era lógico e racional 
admitir a chegada dos primeiros povos americanos pelo estreito de Bering, nem lógico e racional presumir a origem da espécie humana na América Latina. Portanto, persistia a questão: qual a origem dos povos americanos? E, por suposto, qual era a origem dos povos guaranis?

Moisés Bertoni, contrastando sua empiria cartesiana com seus estudos de antropologia linguística guarani, que indicava um idioma primitivo de um mesmo povo ancestral, vislumbrou uma hipótese alternativa: a Polinésia. Mas, como populações inteiras teriam atravessado o grande Oceano Pacífico em tempos tão remotos que o faziam duvidar ainda mais de um desenvolvimento tecnológico para tal façanha? Foi assim que sua explicação se construiu: um continente submerso entre a Polinesia e a América Latina, que permitiu aos povos originários caminharem por onde hoje é o Oceano Pacífico. As mudanças geológicas impediriam que tal monumento geográfico fosse conhecido naquele momento, mas o avanço das pesquisas fatalmente poderia encontrar o que chamou de Arquinesia, o continente submerso. E, deste continente submerso, teria emergido o ancestral comum das populações guaranis que dominaram todo o Caribe e a América do Sul (BERTONI, 1922).

Ora, para além das buscas por uma verdade científica, interessa aqui as relações sociais e culturais que permeavam a produção científica de Bertoni. Assim, se partirmos da premissa de Kathryn Woodward de que a identidade é sempre relacional e é marcada pela diferença, as identidades não são fixas, mas móveis tanto no presente quanto no passado (WOODWARD, 2000), a ciência de Bertoni fixou representações e identidades sobre o passado pré-colombiano da América Latina. Se levarmos ainda em consideração o que Joël Candau diz sobre como as relações entre nação e identidade levam a uma própria relação entre identidade e memória. Esta relação inscreve-se em diferentes práticas, como estabelecer genealogias de origem, para diferenciar memórias que almejam efeitos de verdade ante às lacunas do passado, e erigindo símbolos que deformam, manipulam ou diferenciam o passado e os grupos que o disputam (CANDAU, 2011).

Neste sentido, o amálgama entre suas leituras de toda uma literatura colonial, com suas leituras das mais recentes pesquisas sobre o passado pré-colombiano e somadas ainda à suas próprias pesquisas de antropologia linguística e seus debates com outros autores que também buscavam propor modelos alternativos de compreensão daquelas questões, seria possível dizer que o que Bertoni fez foi definir um lugar para as populações guaranis como memória nacional do Paraguai? Esta é uma questão que ainda precisa ser melhor desenvolvida, mas que se apresenta pertinente neste momento. 


\section{Considerações Finais}

Do exposto, conclui-se que os estudos de Moisés Bertoni foram importantes na medida em que retomam escritos coloniais, fazendo uma vasta leitura comparativa e procurando conectar ou elucidar pontos de diferentes autores da América espanhola. Bertoni ousou propor hipóteses diferentes do status quo sobre a explicação do povoamento da América a partir do estreito de Bering - algo que atualmente é muito mais factível na arqueologia americana, que já não trabalha mais com a hipótese de origem dos povos americanos de um componente genético único e beringista, e sim em diferentes momentos no tempo e no espaço, inclusive via Polinesia.

Entretanto, Bertoni estava errado. A Arquinesia não existia sob as águas do Pacífico. Mesmo assim, é interessante notar que sua ação não foi isolada, e se inseriu num circuito de debates sobre o tema. Mesmo que suas teses não tenham alcançado consenso nem comprovação, seu esforço científico demonstra o vão criativo deixado entre o experimento, as premissas e a lógica racionalizadora da ciência. Se a Arquinesia não existe - e nunca existiu fora do pensamento de Bertoni - a contestação ao Estreito de Bering como única via explicativa frutificou para outras análises posteriores, principalmente com o advento de avanços tecnológicos como os testes químicos por carbono 14 pelo químico Willard Libby, desenvolvido em 1947, menos de duas décadas após a morte de Bertoni, e que permitiu lançar novos olhares sobre a mesma questão, mas com maior precisão no tempo.

Assim, para seguir com esta pesquisa, a discussão sobre o passado pré-colombiano latino-americano deve estar, necessariamente ligado ao contexto da consolidação de um estado-nação paraguaio que viveu Moisés Bertoni, que foi basilar na sua interpretação da América. Cabe investigar em outros trabalhos a relação entre essa leitura da América guarani com o contexto de reconstrução da identidade nacional paraguaia que o autor viveu no Paraguai. Qual o impacto social e cultural da busca destes cientistas em reconstruir o passado e buscar reabilitar identidades e memórias indígenas? Em que medida as construções científicas silenciam ou evidenciam as próprias narrativas indígenas de origem e passado? Ao narrar uma história americana guarani, Bertoni valoriza uma história indígena ou atualiza a visão eurocêntrica da conquista? Questões ainda por discutir.

Deste modo, para avançar na compreensão que os cientistas do período formularam acerca das populações indígenas, principalmente em suas narrativas de origem, é importante continuar os estudos acerca da constituição do circuito cientifico latino-americano nos congressos locais e também na ascensão da arqueologia americana. 


\section{Referências}

BERTONI, Moisés. La Civilización Guarani. Puerto Bertoni: Ex Sylvis, 1922.

CANDAU, Joël. O jogo social da memória e da identidade (2): fundar, construir. In: . Memória e Identidade. São Paulo: Contexto, 2011, p. 135-179.

CHARTIER, Roger. A mão do autor e a mente do editor. Assis: Editora UNESP, 2014.

FOUCAULT, Michel. A Ordem do Discurso. São Paulo: Edições Loyola, 2014.

FLECK, Eliane Cristina Deckmann. A abordagem historiográfca dos séculos XIX e XX sobre a atuação de médicos e boticários jesuítas na América platina no século XVIII. História, Ciências, Saúde - Manguinhos, Rio de Janeiro, v.21, n.2, abr.-jun. 2014, p. 667685.

NIEMEYER, Aline; BUTTURA, Evaldo. Moisés Bertoni: Uma vida para a Ciência. Foz do Iguaçu: Editora Epígrafe, 2012.

TODOROV, Tzvetan. A conquista da América: a questão do outro. São Paulo, SP: Martins Fontes, 1982.

WOODWARD, Kathryn. Identidade e diferença: uma introdução teórica e conceitual. In: SILVA, Tomaz Tadeu da (Org); HALL, Stuart; WOODWARD, Kathryn. Identidade $e$ Diferença: a perspectiva dos estudos culturais. $4^{\text {a }}$. Ed. Petrópolis: Vozes, 2000. p. 7-72. 